\title{
Evaluation of the Exposure to Electromagnetic Fields in Computer Labs of Schools*
}

\author{
Isidor Kokalari ${ }^{1}$, Theodhor Karaja ${ }^{2}$ \\ ${ }^{1}$ Department of Physics, University of Gjirokastra, 6002 Gjirokastra, Albania; ${ }^{2}$ Department of Physics, University of Tirana, Tirana, \\ Albania. \\ Email: ikokalari@uogj.edu.al
}

Received April 10 $0^{\text {th }}, 2010$; revised May 12 $2^{\text {th }}, 2011$; accepted May 20 ${ }^{\text {th }}, 2011$.

\begin{abstract}
Personal computers, apart from being ubiquitous in our everyday activity, very often have been object of study for eventual negative health consequences. During the recent years, a great number of schools in Albania are equipped with lab rooms for teaching computer skills. This has motivated us to carry out a campaign of measuring the intensity of electric and magnetic fields is such places in the schools of Gjirokastra. This paper presents the results of such a study for the evaluation of the possible hazard related to the exposure to this "electro-smog" of the students and teachers. This is done by comparing the measured values of physical quantities with the respective limits and standards recommended by scientists and established by European directives such as 2004/40/CE and 1999/519/CE.
\end{abstract}

Keywords: Electromagnetic Field, Health Effects, Non-Ionizing Radiation, TCO Requirements, Video Display Unit

\section{Introduction}

Nowadays, computers are transformed from a personal working tool to mass communication equipment in the whole planet, causing a revolution in the way of working, getting information and communication.

The increasing use of the computers in working places and schools has raised the worry about possible health dangers [1,2]. Many individuals, who work in computer, have reported various symptoms and job-related complaints, such as sight disquietude, muscle pains, etc. The level of discomfort and complaints appears to increase with the time of computer use [3-5]. However, based on actual studies, there are quite a few plausibility that the use of computers causes permanent changes of eyesight or even damages of the eye itself $[6,7]$.

Computers, like most of electrical appliances, emit both ionizing and non ionizing radiation [8]. Most critical device in respect of electromagnetic radiation is computer video display unit (VDU); most of them in our country still are of cathode ray tube (CRT) type. A VDU emits in almost the entire electromagnetic spectrum [9]. The optical radiation emitted includes visible light (VIS) which forms the image that the VDU is intended to produce; very small amounts of ultraviolet (UV) are emitted from the tube; infrared (IR) appears as heat dissipated by

* Paper publication sponsored by University of Gjirokastra, Albania. the unit. Electric and magnetic fields are emitted in three different frequency ranges. Extremely low frequency (ELF) fields at 50 or $60 \mathrm{~Hz}$ come from the power supply, and the vertical deflection coils. The horizontal deflection coils emit fields operating mainly in the frequencies $15-35 \mathrm{kHz}$. Weak signals at radio frequencies (RF) come from the VDU's interior electronic circuitry and signals received from the computer. Very low-energy X-rays are produced inside the CRT, but the glass screen is thick eNough to completely absorb them [2]. Electrons striking the front of the screen produce static electric fields.

Non ionizing radiation is found in a wide range of occupational settings and can pose a health risk to exposed workers if Not properly controlled [10]. Meanwhile, the scientific research has led towards the use of new technology equipments, which emit less radiation.

\section{Materials and Methodology}

In this study there are presented the results taken by direct measurements of electric and magnetic fields of low frequencies ELF and VLF, as well as electromagnetic fields of high frequencies RF, (which present the highest exposure [11] by VDU-s), in 4 computer lab-rooms of 3 high schools of Gjirokastra town.

Initially the measurements are carried out for a single VDU, $30 \mathrm{~cm}$ in front and $50 \mathrm{~cm}$ around, in accordance 
with the technical procedures established by European standards [12] and international recommendations TCO [13], finding so the values of the intensity of the electric field $E(\mathrm{~V} / \mathrm{m})$ and magnetic inductance $B(\mu \mathrm{T})$ for low frequencies. Later, there are carried out direct measurements of electric field intensity $E(\mathrm{~V} / \mathrm{m})$ and power density $S\left(\mu \mathrm{W} / \mathrm{cm}^{2}\right)$ for Non ionizing radiation emissions in high frequency fields. Measurements were made at maximum intensity in order to obtain "worst case" operating conditions [14].

Afterwards, direct measurements of these physical quantities are carried out in various working positions of the students and teacher in these classrooms for computer science teaching. The attention in taking these measurements is mainly focused towards the effects on the operator of Non ionizing electromagnetic radiation, emitted by VDU-s, and not towards the exact localization or concrete shape of emitting source.

In order to deduct conclusions about the exposure level of students and teachers to Non ionizing electromagnetic fields in the computer labs of these schools, the results of the measurements are compared with the respective limiting international recommendations. The technical Normative with respect to VDU-s take care mostly for the setup of the working place such as to offer safety by the visual, thermal and acoustic point of view.

Concerning the hazards related to Non ionizing radiation, international recommendations of ICNIRP [15] are commonly used, to which the European directives refer (2004/40/CE, 1999/519/CE). But in the case of radiation emitted by VDU-s these are used only for RF emissions.

In the recent years, the scientific studies refer mostly to TCO requirements, which has established in the low frequencies range, much stronger protective limitations than ICNIRP. These requirements are evolved parallel with new and safer technologies in years $(1992,1995$, 1999, 2003, 2006), by even putting restrictions on all computer parts technical specifications such as those regarding energy saving, electrical safety, etc. The TCO recommendations for the protection by electromagnetic emissions of VDU-s are presented in Table 1.

\subsection{Places of Interest}

Measurements are carried out in four lab-rooms of three high schools of Gjirokastra town. The criterions for the selection of these labs were: the type of monitor used (CRT or LCD), the position of the monitors in the classroom (around the walls or in the center of the classroom); as well as the quantity of the monitors in classrooms with different dimensions (the equipment density).

\subsection{Equipments Used for Measurements}

- Anisotropic sensor for electric and magnetic fields
Table 1. International recommendations for protection by VDU radiations.

\begin{tabular}{lll}
\hline & $\begin{array}{l}\text { TCO'92('95, '99,'03, } \\
\text { '06) } 50 \mathrm{~cm} \text { around } \\
\& 30 \mathrm{~cm} \text { in front }\end{array}$ & ICNIRP \\
\hline $\begin{array}{l}\text { Low frequency } \\
(5 \mathrm{~Hz}-2000 \mathrm{~Hz})\end{array}$ & $\mathrm{E}_{\max }=10 \mathrm{~V} / \mathrm{m}$ & $\mathrm{B}_{\max }=0.20 \mathrm{mT}$ \\
$\begin{array}{l}\text { Low frequency } \\
(2 \mathrm{kHz}-400 \mathrm{kHz})\end{array}$ & $\mathrm{E}_{\max }=1 \mathrm{~V} / \mathrm{m}$ & \\
& $\mathrm{B}_{\max }=0.025 \mathrm{mT}$ & $\mathrm{E}_{\max }=61 \mathrm{~V} / \mathrm{m}$ \\
$\begin{array}{l}\text { High frequency } \\
(0,3-300 \mathrm{MHz})\end{array}$ & & $\mathrm{S}_{\max }=1000 \mu \mathrm{W} / \mathrm{cm}^{2}$ \\
\hline
\end{tabular}

ELF, model EMFields PRO. It has a digital readout and measures electric and magnetic fields with frequencies from 10 to $2000 \mathrm{~Hz}( \pm 3 \mathrm{~dB})$. The magnetic scale has a resolution of $0.01 \mu \mathrm{T}$ and a full scale of $19.99 \mu \mathrm{T}$. The electric scale has a resolution of $1 \mathrm{~V} / \mathrm{m}$ and a full scale of $1999 \mathrm{~V} / \mathrm{m}$ (with accuracy of $\pm 2 \%$ ). This hand-held instrument can be used, at home and in the workplace, to measure the fields from electric power sources - overhead lines, underground cables, house wiring, electrical appliances and equipment, etc.

- Holaday Instruments, model HI-3604 anisotropic sensor for extremely low frequency (ELF) electric and magnetic fields. It is appropriate for detection of electric fields in the frequency range $20 \mathrm{~Hz}-5 \mathrm{kHz}$ and magnetic fields in the frequency range $40 \mathrm{~Hz}-1 \mathrm{kHz}$. The output linearity is close to $1(0.96-1.04)$ for changes of the inductance B in the range $0.2 \mu \mathrm{T}-1 \mathrm{mT}$.

- Isotropic sensor for radio-frequencies, model Chauvin-Arnoux CA43, operative in the frequency range between $100 \mathrm{kHz}$ and 2,5 GHz. The sensor is capable to measure values of electric field from $0.1 \mathrm{~V} / \mathrm{m}$ to $199.9 \mathrm{~V} / \mathrm{m}$ with a resolution of $0.1 \mathrm{~V} / \mathrm{m}$ and accuracy $1 \mathrm{~dB}$. It can measure also the power density between $0.1 \mu \mathrm{W} / \mathrm{cm}^{2}$ and $1999 \mu \mathrm{W} / \mathrm{cm}^{2}$; with resolution 0.1 $\mu \mathrm{W} / \mathrm{cm}^{2}$ and accuracy $1 \mathrm{~dB}$ in the range $0.1-199.9$ $\mu \mathrm{W} / \mathrm{cm}^{2}$ and, with resolution $1 \mu \mathrm{W} / \mathrm{cm}^{2}$ and accuracy $2 \mathrm{~dB}$ in the range $200-1999 \mu \mathrm{W} / \mathrm{cm}^{2}$. It is capable also to store data in a PC.

\section{Results and Discussions}

\subsection{Pedagogical High School "Pandeli Sotiri"}

This lab-room with dimensions $8.5 \times 6 \mathrm{~m}$, is equipped with 15 VDU-s of CRT type, model Samtron 78E, placed around the walls as shown in Figure 1.

Measurements are taken in 5 workplaces: in the teacher's workplace (P1) and in the students' (P2, P3, P4, and P5). The measured values of the electric field intensity and magnetic field inductance for the low frequencies 


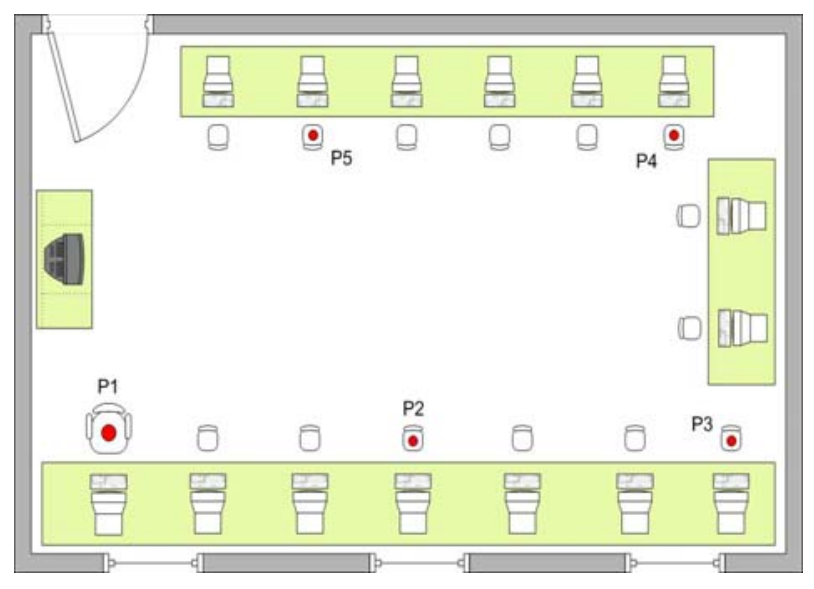

Figure 1. Placement scheme of CRT type VDU-s at "P.Sotiri" high school lab (scale 1:150).

(ELF and VLF), as well as those of power density and electric field intensity for high frequencies (RF) are shown in Table 2. By analyzing such results we conclude as follows:

- Electric field of low frequency results about 12 times higher than the limit.

- Magnetic field of low frequency results in the higher extreme of the recommended limit, but still in good accordance with it. The teacher's workplace (P1) is an exclusion in which the standard is slightly exceeded, but it should be paid the necessary attention to this fact because of the longer stay of the teacher in front of the computer compared to that of the students.

- Power density of electromagnetic fields of high frequencies results over 12 times below the recommended limits.

- Electric field of high frequencies results in average 14 times below the limits.

\subsection{High School “Asim Zeneli” (First Lab)}

This lab-room with dimensions $10 \times 7 \mathrm{~m}$, is equipped with 16 VDU-s of CRT type, model HP 7540, placed around the walls as shown in Figure 2.

Table 2. Results of the measurements carried out in the computer lab of "P.Sotiri" high school.

\begin{tabular}{ccccc}
\hline & \multicolumn{2}{c}{ Low frequency } & \multicolumn{2}{c}{ High frequency } \\
\cline { 2 - 5 } & $\mathrm{E}(\mathrm{V} / \mathrm{m})$ & $\mathrm{B}(\mu \mathrm{T})$ & $\mathrm{S}\left(\mu \mathrm{W} / \mathrm{cm}^{2}\right)$ & $\mathrm{E}(\mathrm{V} / \mathrm{m})$ \\
\hline P1 & 127 & 0.21 & 78.4 & 3.59 \\
P2 & 114 & 0.13 & 82.7 & 4.78 \\
P3 & 124 & 0.18 & 90.3 & 6.29 \\
P4 & 117 & 0.11 & 67.8 & 3.82 \\
P5 & 122 & 0.18 & 52.6 & 3.17 \\
\hline
\end{tabular}

Measurements are taken in 6 workplaces: in the teacher's workplace (A1) and in the students' (A2, A3, A4, A5, and A6). The results of the measurements for low and high frequency radiation in this classroom are presented in Table 3, from which we conclude that:

- Electric field of low frequency results about 3 times higher than the recommended limit. In the workplaces A4 and A5 (next to the Hub and in front of it), this quantity becomes about 35 times higher than the limit. Still, the electric field measured at A6, exceeds 4 times the limit because the student sited in this workplace is exposed even to the back part (where the radiation is maximum) of the monitor A1.

- The magnetic field of low frequency results in good accordance with the limit, excluding here the positions A5 where the standard is slightly exceeded because of the presence of the Hub and the battery system and A6 where the measured value results higher than the standard because of the emission by the back part of the teacher's monitor.

- Power density of electromagnetic field of high frequencies results on average 30 times below the recommended limits.

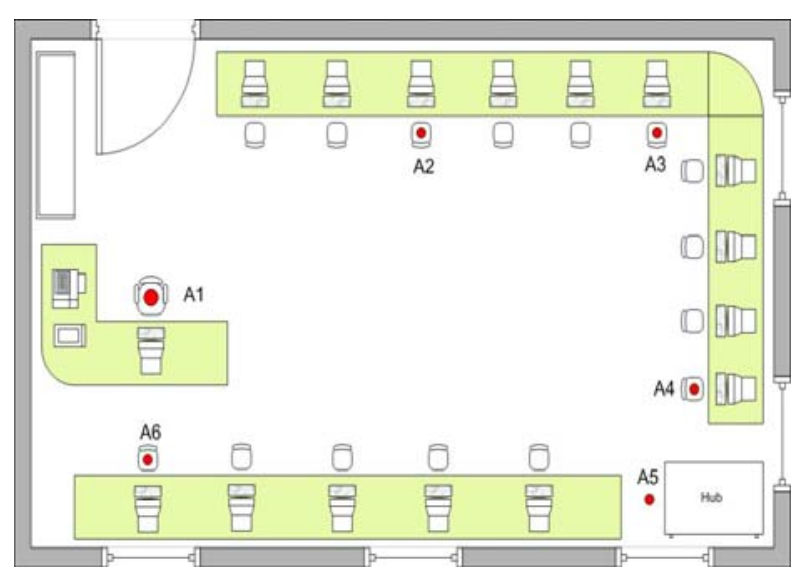

Figure 2. Placement scheme of CRT type VDU-s at “A.Zeneli” high school lab-1 (scale 1:150).

Table 3. Results of the measurements carried out in the computer lab-1 of “A.Zeneli” high school.

\begin{tabular}{ccccc}
\hline & \multicolumn{2}{c}{ Low frequency } & \multicolumn{2}{c}{ High frequency } \\
\cline { 2 - 5 } & $\mathrm{E}(\mathrm{V} / \mathrm{m})$ & $\mathrm{B}(\mu \mathrm{T})$ & $\mathrm{S}\left(\mu \mathrm{W} / \mathrm{cm}^{2}\right)$ & $\mathrm{E}(\mathrm{V} / \mathrm{m})$ \\
\hline A1 & 29 & 0.18 & 13.1 & 1.44 \\
$\mathrm{~A} 2$ & 31 & 0.09 & 35.8 & 2.85 \\
$\mathrm{~A} 3$ & 34 & 0.12 & 49.4 & 4.95 \\
$\mathrm{~A} 4$ & 380 & 0.12 & 26.9 & 2.69 \\
$\mathrm{~A} 5$ & 349 & 0.25 & 36.2 & 3.34 \\
$\mathrm{~A} 6$ & 44 & 0.23 & 73.3 & 4.47 \\
\hline
\end{tabular}


- Electric field of high frequencies results in average 16 times below the limits.

- Measured quantities result in lower values than those taken in "Pandeli Sotiri" high school, where a CRT type VDU is also used, but of an older year of manufacture.

\subsection{High School “Asim Zeneli” (Second Lab)}

This lab-room with dimensions $8.5 \times 5.5 \mathrm{~m}$, is equipped with 18 VDU-s of LCD type, model Acer V173, placed around the walls and in the centre of the room as shown in Figure 3.

Measurements are taken in 5 workplaces: in the teacher's workplace (Z1) and in the students' (Z2, Z3, Z4, and Z5). Analyzing the results of the measurements presented in Table 4, we conclude that:

- Electric field of low frequencies results about 2.5 times higher than the limit.

- Magnetic inductance in the low frequencies results in the extreme of the permitted values, but still in good accordance with it. The position 1 (teacher's place), in which the standard is slightly exceeded, is an exclusion, but it should be paid attention to solve this because the teacher's staying in classroom is longer than that of the students'

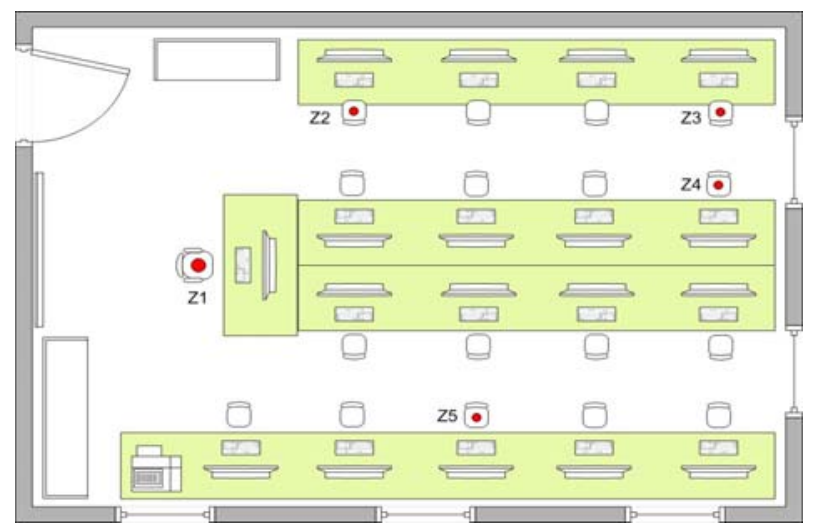

Figure 3. Placement scheme of LCD type VDU-s at “A.Zeneli” high school lab-2 (scale 1:150).

Table 4. Results of the measurements carried out in the computer lab-2 of “A.Zeneli” high school.

\begin{tabular}{ccccc}
\hline & \multicolumn{2}{c}{ Low frequency } & \multicolumn{2}{c}{ High frequency } \\
\cline { 2 - 5 } & $\mathrm{E}(\mathrm{V} / \mathrm{m})$ & $\mathrm{B}(\mu \mathrm{T})$ & $\mathrm{S}\left(\mu \mathrm{W} / \mathrm{cm}^{2}\right)$ & $\mathrm{E}(\mathrm{V} / \mathrm{m})$ \\
\hline $\mathrm{Z} 1$ & 24 & 0.22 & 50.7 & 2.24 \\
$\mathrm{Z} 2$ & 25 & 0.27 & 122.6 & 3.66 \\
$\mathrm{Z} 3$ & 18 & 0.19 & 137.7 & 3.17 \\
$\mathrm{Z} 4$ & 23 & 0.18 & 144.6 & 4.48 \\
$\mathrm{Z} 5$ & 19 & 0.14 & 43.8 & 1.63 \\
\hline
\end{tabular}

- Power density of the electromagnetic field of high frequencies results over 7 times below the recommended limits.

- Electric field of high frequencies results on the average 4 times below the limits.

- Measured values of physical quantities in interest result lower than those measured in the lab-1 of the same school ("Asim Zeneli") where there are used CRT type monitor.

\subsection{High School "Siri Shapllo"}

This classroom with $9 \times 6.5 \mathrm{~m}$ dimensions is equipped, with 13 computers with liquid crystals display monitors (LCD), model Acer V173, placed around the walls as shown in Figure 4.

Measurements are taken in 5 workplaces: in the teacher's workplace (S1) and in the students' (S2, S3, S4, and S5). Table 5 which illustrates the results of the measurements for low and high frequency radiation helps us to conclude that:

- Electric field of low frequencies results about 1.2 times above the recommended limit.

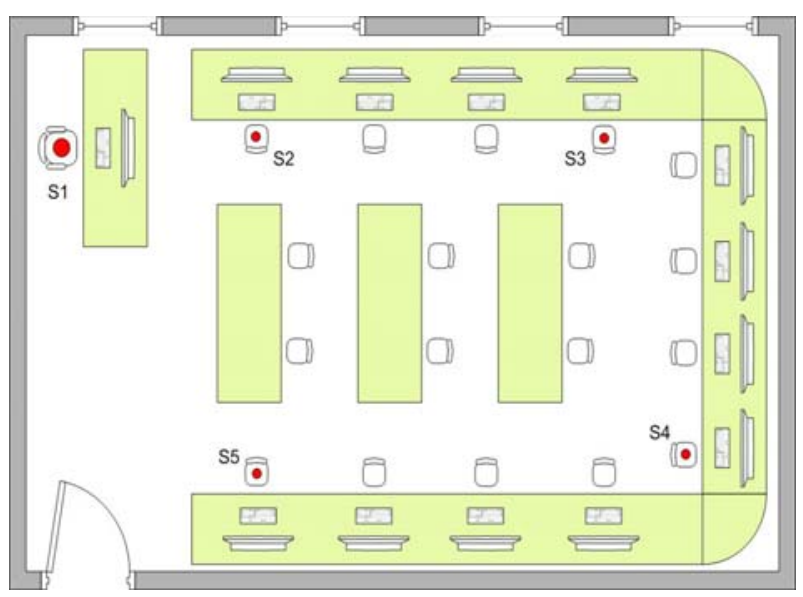

Figure 4. Placement scheme of LCD type VDU-s at “S.Shapllo" high school lab (scale 1:150).

Table 5. Results of the measurements carried out in the computer lab of "S.Shapllo" high school.

\begin{tabular}{ccccc}
\hline & \multicolumn{2}{c}{ Low frequency } & \multicolumn{2}{c}{ High frequency } \\
\cline { 2 - 5 } & $\mathrm{E}(\mathrm{V} / \mathrm{m})$ & $\mathrm{B}(\mu \mathrm{T})$ & $\mathrm{S}\left(\mu \mathrm{W} / \mathrm{cm}^{2}\right)$ & $\mathrm{E}(\mathrm{V} / \mathrm{m})$ \\
\hline S1 & 12 & 0.11 & 28.2 & 2.86 \\
S2 & 11 & 0.09 & 66.6 & 3.98 \\
S3 & 9 & 0.08 & 64.3 & 4.03 \\
S4 & 14 & 0.22 & 43.4 & 4.77 \\
S5 & 16 & 0.18 & 37.2 & 2.69 \\
\hline
\end{tabular}


- Magnetic inductance of low frequencies results in good consistency with the limits. The S4 workplace is an exclusion in which the recommended standard is slightly exceeded, because of the presence of a small Hub placed in the wall above that position.

- The power density of RF electromagnetic field results about 20 times lower than the limits.

- The electric field of high frequency results in average 13 below the limits.

- The quantities measured in this classroom, equipped with LCD type monitors placed around the walls, result in smaller values than those of the lab-2 of "Asim Zeneli" school, where the same type of LCD monitors are used, but positioned in the centre of the class.

\section{Conclusions}

For the first time it is carried out such a detailed study in the informatics lab-rooms of Gjirokastra town schools.

Generally, the measured quantities result with values in good accordance with the recommended limits established for the protection by the Non-ionizing radiations emitted by video display units (VDU).

The physical quantities which better chime with these limits are those measured for the high frequency radiations (power density and electric field intensity).

In respect of low frequency radiation, the electric field results much higher than the permitted limit, but this can be easily shielded, so it is recommended the use of glass filters for the monitors, especially for those of CRT type. The quantity to which it should be paid maximal attention by the point of view of safety and protection, the magnetic inductance, results generally in satisfactory accordance with the recommended limits.

By comparing the exposure according as the type of the monitor (CRT vs. LCD), for the same way of placement in the classroom (around the walls), it results that in all the working places, where measurements are taken, the values of the electric field (of low frequency) and the values of the power density (high frequency) for the classroom equipped with LCD type monitors, are smaller than those for the classroom equipped with CRT type monitors (Tables 2 and $\mathbf{5}$ ).

The comparison of the exposure in relation of how the monitors are placed in the classroom, for the same VDU type (LCD type in this case), shows that in all the positions where measurements are taken, the values of electric field (low frequency) and those of power density (high frequency) for the placement in circle are smaller than the respective values for the central placement (Tables 2 and 5 ).

Counting on the abovementioned conclusions, it is recommended the use in the computer lab-rooms of schools of PCs equipped with LCD type monitors. In preclusion of this, it is recommended the use of protective glass filtering shields over the screens of CRT type monitors to reduce rays emitted from the front.

It is recommended that the computers should be placed around the walls of the lab-room, because it results to be the setup which provides minimal exposure towards the Non ionizing radiation. In such way, the user will not be in vicinity of the back part of the monitor which emits maximally. Continuing such reasoning, it is recommended that No students' desks are positioned in the opposite side of the wall because the most hazardous quantity, the magnetic inductance, can not be shielded by walls or partitions.

It is recommended the placement of additional equipments (UPS, Hub, photocopy machine, printers, etc.) in a proper place far away from the students' workplace.

Finally, in accordance with TCO requirements [13], it is recommended that in the computer lab-rooms, the working places of the students, consequently the PC monitors, should be at least $50 \mathrm{~cm}$ away from each other. This is because the magnetic field strength diminishes rapidly the farther you move from the VDU [5].

\section{Acknowledgments}

Work supported by the bilateral research project "Analysis of the intensity of electric and magnetic fields at 50 $\mathrm{Hz}$ and of the e-m field at $100 \mathrm{kHz}-3 \mathrm{GHz}$ and of their origin" implemented by the Physics Departments of Salento (Italy) and Gjirokastra (Albania) Universities, financed by the Italian Ministry of Foreign Affairs and the Albanian Ministry of Education and Science.

\section{REFERENCES}

[1] A. Ahlborn, E. Cardis, A. Green, et al.,"Review of Epidemiologic Literature on EMF and Health," Environmental Health Perspectives, Vol. 109, No. 6, 2001, pp. 911-933. doi: $10.2307 / 3454653$

[2] WHO Division of Global and Integrated Environmental Health, "Video Display Units (VDUs) and Human Health," Fact Sheet No. 201, July 1998.

[3] National Institute for Occupational Safety and Health, "Potential Health Hazards of Video Display Terminals," US Government Printing Office, Washington, 1981.

[4] M. J. Smith, B. Cohen, L. Stammerjohn, "An InvestiGation of Health Complaints and Job Stress in Video Display Operations," Human Factors: The Journal of the Human Factors and Ergonomics Society, 1981, Vol. 23, No. 4, pp. 387-400.

[5] F. Tarsitano, V. Martino, F. Martire, F. Vinci, "Technical characteristics of Video-Terminals (VDU) and Their Health Effects," Proceeding of 2nd National Congress of Environmental Physics, edited by the Consortium for Research and Application of Innovative Technologies of 
the Physics Department at Calabria University, October 1995, Cosenza, Italy, pp. 123-133.

[6] B. Cole, J. Maddocks and K. Sharpe, "Effects of VDUs on the Eyes: Report of 6-Year Epidemiological Study," Ophthalmology Visual Science, Vol. 73, No. 8, 1996, pp. 512-528. doi:10.1097/00006324-199608000-00001

[7] Council of Scientific Affairs, "Health Effects of Video Display Terminals," Journal of American Medical Association, Vol. 257, No. 11, 1987, pp. 1508-1512. doi: 10.1001/jama.1987.03390110084032

[8] P. Kanapeckas, S. Maciulevičius, A. Otas, V. Petrauskas and A. Valys, "Electromagnetic Radiation at Computerized Workplaces," Information TechNology and Control, Vol. 36, No. 4, 2007, pp. 348-352.

[9] WHO Division of Global and Integrated Environmental Health, "Provisional Statements of WHO on Occupational Health Aspects in the Use of VDUs," VDT News, Vol. 3, No. 1, 1986, p. 13.

[10] I. Kokalari, "Evaluation of the Exposure to Electromagnetic Fields in Gjirokastra Region," Journal of Electromagnetic
Analysis and Applications, Vol. 2, No. 5, 2010, pp. 283-286. doi: $10.4236 /$ jemaa.2010.25036

[11] F. Catalano, "Lenti Protettive per Radiazioni da PC," Optometria, Vol. 25, 2002, pp. 8-15.

[12] prEN 50279, "Visual Display Units - Measuring Methods for Low Frequency Electric and Magnetic Near Fields," European Electro Technical Standardization Committee, 1998.

[13] TCO'03 Displays, "Mandatory and Recommended Requirements for CRT-Type Visual Display Units (VDUs)," TCO Development, 2005.

[14] I. Kokalari, "Metodika e Vlerësimit të Ekspozimit Ndaj fushave Elektromagnetike Jo Jonizuese," Matematika dhe Shkencat e Natyrës, Kërkime Universitare, No. 15, 2007, pp. 54-67.

[15] International Commission on Non-Ionizing Radiation Protection, "Guidelines for Limiting Exposure to TimeVarying Electric, Magnetic and Electromagnetic Fields (Up to $300 \mathrm{GHz}$ )," Health Physics, Vol. 74, No. 4, 1998, pp. 494-522. 